developed her episode of coronary occlusion as early as the thirteenth week of gestation and she was the only one in our series in whom the serum cholesterol was significantly raised.

The diagnosis of myocardial infarction during pregnancy presents clinical and electrocardiographic difficulties. Accessory laboratory investigations for myocardial necrosis have to be interpreted with reservations. Upper abdominal pain, flatulence, and even chest discomfort are so common during normal pregnancy that they may mask ischaemic heart pain. The true nature of such symptoms may be obvious only retrospectively when an incidental electrocardiogram is recorded, as in the case reported by Watson et al. (1960). Normally the erythrocyte sedimentation rate increases progressively, reflecting changes in plasma proteins. Leucocytosis occurs, and at term the white cell count may be as high as $15,000 / \mathrm{cu}$. mm. (Tysoe and Lowenstein, 1950). There is evidence that normally the serum aspartate aminotransferase activity does not deviate, though it may be elevated in toxaemia of pregnancy (Crisp et al., 1959). Serum lactic dehydrogenase is a much less reliable index of myocardial necrosis, as it may be raised in normal pregnancy, and in particular during the puerperium. According to Smith and Gatenby (1958) this enzyme is elevated in $18 \%$ of antepartum patients and in $100 \%$ of postpartum patients.

Objective evidence of myocardial infarction, therefore, will depend on electrocardiographic analysis, and account must be taken of the electrocardiographic changes which may occur during pregnancy when the heart is not primarily involved. In the later months the mean QRS axis may rotate leftwards owing to elevation of the diaphragm (Hollander and Crawford, 1943) and a deep Q deflection may appear in lead III (Thomson et al., 1938). Acute pulmonary embolism may produce abnormal $Q$ deflections, especially in lead III and S-T T segment and $\mathrm{T}$-wave changes, which may mimic postero-diaphragmatic infarction. In addition, electrolyte imbalance may alter the voltage and polarity of the $T$ waves. Intrinsic myorardial disease other than infarction, such as myocarditis of pregnancy, may produce electrocardiographic changes indistinguishable from infarction. In short, electrocardiographic abnormalities must be correlated with all the clinical data. The, subsequent history of our patients supports the view that the grossly abnormal tracings were in fact due to myocardial infarction.

\section{Summary}

Acute myocardial infarction is rare in pregnancy. The cases of five elderly multigravidae suffering from this condition are described. The diagnosis during pregnancy may present clinical and electrocardiographic difficulties. The increased load on the heart and changes in the blood lipids may predispose to acute infarction in late pregnancy in women with pre-existing coronary atherosclerosis.

Our thanks are due to our obstetric colleagues of the Jubilee and Gardner Robb Maternity Hospitals, who kindly referred their patients to us for cardiac assessment.

\section{REFERENCES}

Barr, D. P. (1953). Circulation, 8, 641.

Bedford, J. R. D. (1964). F. Obstet. Gynaec. Brit. Cwlth, 71, 459.

Crisp, W. E., Miesfeld, R. L., and Frajola, W. J. (1959). Obstet. and Gynec., 13, 487.

Hollander, A. G., and Crawford, J. H. (1943). Amer. Heart f., 26, 364.

Katz, H. (1921). Arch. Gynäk., 115, 283.

Magner, D. (1961). ₹. Obstet. Gynaec. Brit. Cwlth, 68, 128.

Mendelson, C. L. (1960). Cardiac Disease in Pregnancy. Philadelphia.

Oliver, M. F. and Boyd, G. S. (1955). Clin. Sci., 14, 15.

Reis, R. A., and Frankenthal, L. E. (1935). Amer. F. Obstet. Gynec., 29, 44.

Smith, W. S., and Gatenby, P. B. B. (1958). Irish f. med. Sci., p. 457.

Thomson, K. J., Cohen, M. E, and Hamilton, B. E. (1938). Amer. ₹. med. Sci., 196, 819.

Tysoe, F. W., and Lowenstein, L. (1950). Amer. F. Obstet. Gynec., 60, 1187.

Watson, H., Emslie-Smith, D., Herring, J., and Hill, I. G. W. (1960). Lancet, 2, 523.

\title{
Oil Mist Hazard and Piped Air Supplies
}

\author{
JOHN A. BUSHMAN,* L.M.S.S.A. ; PETER A. CLARK, $†$ M.B., M.C.PATH.
}

During recent years there has been a considerable increase in the use of piped air supplies in hospitals. In intensive therapy units this air may often be used to ventilate patients directly.

A system of this type was installed in the intensive therapy unit at Barnet General Hospital and has been in regular use from January 1965. The supply was provided by duplicate oil-lubricated Lacey-Hulbert compressors, each capable of delivering $5 \frac{1}{2} \mathrm{cu}$. ft. $(0.156 \mathrm{cu}$. m.) of air per minute at $100 \mathrm{lb} . /$ sq. in. (7 kg./sq. cm.). These compressors were installed in the cellar below the intensive therapy unit, together with a reservoir of $33 \mathrm{cu}$. ft. $(0.935 \mathrm{cu}$. m.) capacity. A Hymatic "rectifier" was installed to remove water. The compressed air was delivered by copper piping to five bedside outlets each equipped with B.O.C. flowmeters.

Some months later it was noticed that some of the flowmeter bobbins were inclined to stick. One of the flowmeters appeared to be slightly oily, and the possibility of oil mist contamination

\footnotetext{
* Anaesthetic Registrar, Barnet General Hospital, Barnet, Herts. Research Fellow, Department of Anaesthesia, University of Birmingham. t Consultant Pathologist, Barnet General Hospital, Barnet, Herts.
}

was considered. When the valve of this flowmeter was completely opened to a point far beyond its normal setting, a ripple of oil could be seen on the side of the meter tube (Fig. 1). This excessive air flow had presumably dislodged a quantity of oil trapped below the valve.

An investigation to find the extent of this oil contamination was started. In view of the extremely small quantities of oil mist likely to be present in the air, it was decided to use a fluorimetric technique for oil estimation (Parker and Barnes, 1960).

\section{Methods}

Oil mist was collected by passing a known volume of air through filter paper held in a special device consisting of two recessed flanges fitted with hose connexions between which pairs of filter paper discs were held by washers and a spacer. The filter papers used in this work were Whatman paper No. 41, which will cope with low-pressure flows of at least 10 litres per minute. Owing to the rather open nature of the paper, two discs were used in each flange. The papers were 
prepared by washing twice with spectroscopic quality cyclohexane (Spectrosol grade-Hopkins \& Williams Limited).

The collection device was attached by plastic tubing to the outlet of a flowmeter previously cleaned by washing with cyclohexane. The compressed air was allowed to flow at a known rate for varying periods of time, depending on the amount of oil expected to be present. The collection periods varied from

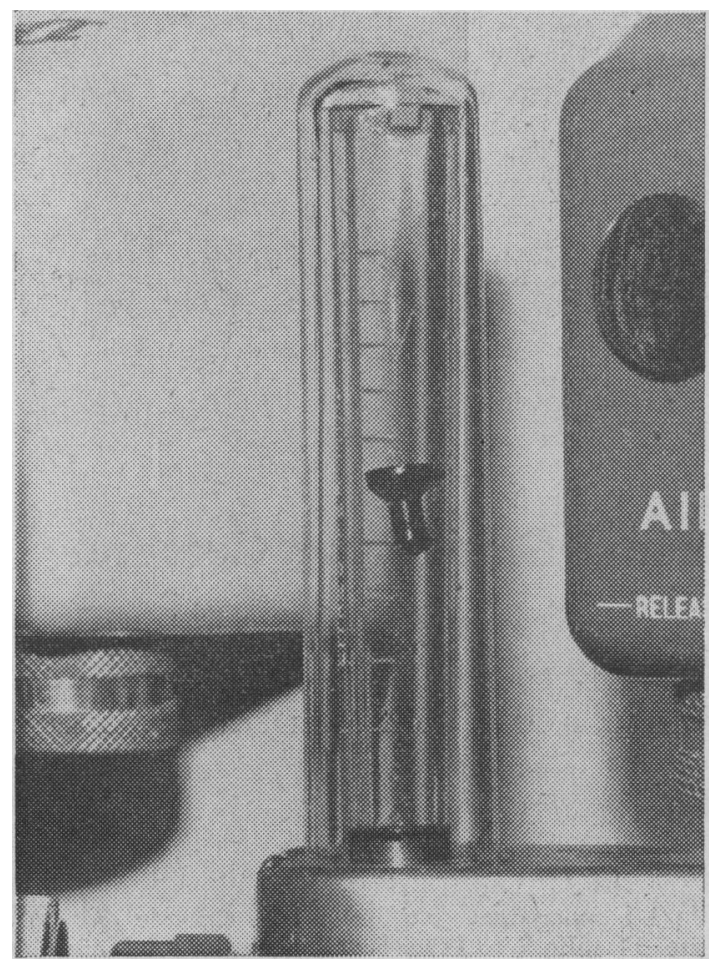

Frg. 1.-Air flowmeter showing ripple of oil when valve fully opened.

one hour after starting the compressor, following emptying the reservoir, to five days after the fitting of the filter system for the removal of oil mist.

After the collection period the central areas of the filter papers which had been in contact with the air channel of the collecting device were cut out and shaken with cyclohexane to extract any

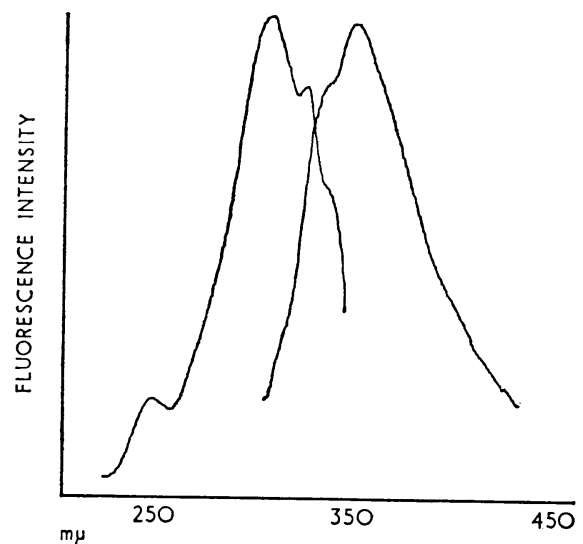

FIG 2.-Excitation (left-hand curve) and fluorescence (right-hand curve) spectra of crankcase oil.

trapped oil. The fluorescence of the resulting extracts was read in a Baird-Atomic Fluorescence Spectrophotometer, model SF.1. Under the conditions used it was found that the fluorescence of Shell Talpa 40 oil used in the compressors was maximal at a wavelength of $350 \mathrm{~m} \mu$ using excitation at $300 \mathrm{~m} \mu$ (Fig. 2).

As it was thought possible that the wick-feed lubrication system concentrated oil in the compressor cylinders after a period of rest, an oil collection was made from air in the reservoir after a 24-hour period during which the compressors had not been run. The reservoir was then emptied and a second sample taken immediately after the compressors had refilled the reservoir.

When the possibility of oil contamination had been confirmed, the British Oxygen Company (who had installed the system) were informed, and they carried out considerable work on the system. This involved the complete cleaning of all equipment, copper piping being replaced wherever easily accessible. The compressors were serviced and arrangements made to drain the excess oil from the sumps at daily intervals. In addition Vokes SPL 10 filters were fitted into the system at points where the air lines entered the intensive therapy unit.

\section{Results}

All estimations were made with an air flow of 10 litres per minute. Under the ordinary working conditions of the unit the average amount of oil leaving each flowmeter was $18 \mu \mathrm{g}$. per hour. Under the same conditions the amount of oil trapped in the flowmeter was $230 \mu \mathrm{g}$. per hour.

After the compressors had been switched off for 24 hours only $6 \mu \mathrm{g}$. of oil per hour could be detected in the air leaving a flowmeter attached to the reservoir. After emptying and refilling the reservoir the oil level rose to $70 \mu \mathrm{g}$. per hour. After fitting the Vokes SPL 10 filter system, no oil could be detected even in collections lasting 120 hours. After six months' use of the filters no oil could be detected in a 120-hour collection.

\section{Discussion}

It seems probable that oil mist contamination of piped air supplies may be a real problem. There appears to have been relatively little work on the problem of oil contamination, though Gerarde (1962) and Cushing and Miller (1965) indicate that chemical pneumonitis may well occur. Although our work has not included any specific estimation of oil particle size, it seems likely, from the relatively small amounts of oil being found, that particle size must be very small.

The provision of oil-free air can be made in two ways-by prevention of oil entering the air at the compressor or by removal of oil found in the compressed air. It is possible to provide oil-free air direct from certain types of compressor, but these are either very expensive or of limited capacity. Compressed air can, of course, be provided from a battery of commercially supplied cylinders, this air having been compressed by a water-lubricated pump and therefore free from oil. However, this is a most expensive method and the cost would be prohibitive in a unit such as ours, where several patients may be ventilated for periods of weeks or even months.

The technology of oil-lubricated pumps is well understood. They are very reliable, relatively cheap, and readily available. Once the use of oil-lubricated pumps is accepted, the problem becomes one of removing the oil mist, either by filtration or by other means.

To be acceptable, a filter, in addition to efficiently removing the oil, must cause a relatively small pressure drop, be able to operate at a flow rate well in excess of the maximum demand, and be safe at the working pressure of the system. From a practical point of view, it is also essential that the filters should be arranged in such a way that they may be changed while the system is in operation. To this end the British Oxygen Company have fitted a system using Vokes SPL 10 filters equipped with replaceable cartridges No. C.74247. Two of these filters are arranged in parallel, so that the air supply can be maintained while one of the filters is being removed for inspection. These filters deal with oil particles. Oil vapour can be removed 
by techniques based on absorption, but the cost and maintenance of apparatus of this type make their use impracticable.

During the course of several months, usage of this system has proved satisfactory, and we regard this as an acceptable technique for the removal of oil contamination. Though the filters do not appear to be passing detectable oil after several months' use, it seems reasonable to change the filter elements, costing about 30 s. each, at quarterly intervals.

\section{Summary}

Patients in an intensive therapy unit were being directly ventilated with air from a piped system. It was suspected that this air could be contaminated by oil mist from the compressors used in the system.

By passing the compressed air through a collection device, it was possible to extract oil in microgram quantities, which were subsequently estimated by spectrofluorimetry. Oil contamination was studied under various working conditions.

Because of the implication of oil mist contamination, successful modifications were made to the air-supply system. Even when collections have been made for several days, oil contamination is now below the level of detection.

We would like to acknowledge the co-operation of the British Oxygen Company, and in particular Messrs. J. Cartwright and V. Owen, who have shown the greatest interest in this problem.

Requests for reprints to be made to Dr. P. A. Clark, consultant pathologist, Barnet General Hospital, Wellhouse Lane, Barnet, Herts.

REFERENCES

Cushing, I. E., and Miller, W. F. (1965). Respiratory Therapy, edited by P. Safar, p. 186. Oxford.

Gerarde, H. W. (1962). Industrial Hygiene and Toxicology, vol. 2, 2nd ed., edited by F. A. Patty, p. 1201.

Parker, C. A., and Barnes, W. J. (1960). Analyst, 85, 3.

\title{
Bronchial Carcinoma with Hypercalcaemia Simulating Cerebral Metastases
}

\author{
N. J. STRICKLAND,* M.A., M.B., B.CHIR.; A. M. BOLD, † M.A., B.M., B.CH.; W. E. MEDD,
}

The occurrence of hypercalcaemia in patients with a neoplasm without bony metastases has been recognized for some years. The symptoms and signs of hypercalcaemia may dominate the clinical picture. In particular, vomiting and mental disturbance might lead to an erroneous diagnosis of cerebral metastases, so that surgical removal of the primary growth is not attempted and a hopeless prognosis is given. Correct diagnosis with excision of the neoplasm may lead to symptomatic and biochemical recovery. The following case illustrates these points.

\section{Case Report}

A woman aged 54 complained of nausea and vomiting since an attack of diarrhoea three weeks previously. The vomiting occurred regardless of eating, and there was no abdominal pain or indigestion. She had also noticed lethargy, weakness, impairment of concentration and reasoning, and had had hiccups on and off for a month. She had always been constipated, and had passed urine once nightly for six months. She had lost 1 stone $(6.4 \mathrm{~kg}$.) in weight. She had had a cough since an episode of influenza eight months previously, and had smoked 30 cigarettes a day until 18 months before admission.

On examination there was moderately severe weakness of hip flexion and knee extension, and slight weakness of knee flexion on both sides. Her mental concentration was impaired. She sometimes used the wrong words, and her performance at "serial sevens" was impaired.

\section{Investigations}

The serum calcium and phosphorus results are given in the Table. Hb 13.9 g./100 ml. ; W.B.C. 9,200/cu. mm. ; E.S.R. $70 \mathrm{~mm}$. in one hour ; blood urea $28 \mathrm{mg} . / 100 \mathrm{ml}$. Plasma electrolytes: sodium

\footnotetext{
* Medical Registrar, Kingston Hospital, Kingston-upon-Thames, Surrey. † Senior Registrar in Biochemistry, Kingston Hospital, Kingston-uponThames, Surrey.

‡ Consultant Physician, Kingston Hospital, Kingston-upon-Thames,
} Surrey.
$144 \mathrm{mEq} / 1$. ; potassium $3.6 \mathrm{mEq} / 1$. ; chloride $94 \mathrm{mEq} / 1$. ; bicarbonate $34 \mathrm{mEq} / \mathrm{l}$. Liver-function tests: total bilirubin less than $0.5 \mathrm{mg} . / 100 \mathrm{ml}$; thymol turbidity 2.5 units ; cholesterol 260 mg./100 ml. ; alkaline phosphatase 11 K.A. units; S.G.O.T. 15 sigma units; S.G.P.T. 10 sigma units; serum albumin 4.9 g./100 $\mathrm{ml}$; serum globulin $2.9 \mathrm{~g} . / 100 \mathrm{ml}$.; electrophoresis: increase in $\alpha_{1}$ - and $\alpha_{2}$-globulin and mucoprotein.

Results of Serum Calcium and Phosphorus Determinations Before and

\begin{tabular}{|c|c|c|}
\hline Date & $\begin{array}{l}\text { Serum Calcium } \\
(\mathrm{mg} . / 100 \mathrm{ml} .)\end{array}$ & $\begin{array}{l}\text { Serum Phosphorus } \\
\text { (mg./100 ml.) }\end{array}$ \\
\hline $\begin{array}{c}3 / 9 / 64 \\
5 / 9 / 64 \\
7 / 9 / 64 \\
\text { Preop. } \\
\text { Preop. } \\
\text { Postop. (4 p.m.) } \\
\text { Midnight } \\
20 / 9 / 64 \\
21 / 9 / 64 \\
22 / 964 \\
25 / 9 / 64 \\
26 / 9 / 64 \\
28 / 9 / 64 \\
30 / 9 / 64 \\
2 / 1064 \\
12 / 11 / 64 \\
15 / 2 / 65 \\
26 / 6 / 65 \\
24 / 8 / 65 \\
15 / 2 / 66\end{array}$ & $\begin{array}{c}16.4 \\
15.7 \\
16.9 \\
\text { Broken } \\
11.8 \\
11.3 \\
10.3 \\
10.4 \\
9.1 \\
9.1 \\
8.8 \\
9.1 \\
9.1 \\
9.5 \\
10.3 \\
10.1 \\
10.5 \\
10.0 \\
9.8\end{array}$ & $\begin{array}{l}\overline{2} \\
1.9 \\
2.3 \\
3 \cdot 1 \\
2 \cdot 4 \\
2.1 \\
1.9 \\
3 \cdot 4 \\
3.3 \\
3.2 \\
4.1 \\
3.6 \\
4 \cdot 4 \\
4.1 \\
4 \cdot 0\end{array}$ \\
\hline
\end{tabular}

Creatinine clearance $84 \mathrm{ml} . / \mathrm{min}$; urine calcium $136 \mathrm{mg} . / 24$ hours ; renal phosphate excretion index, +0.09 (normal $0 \pm 0.09-$ Nordin and Fraser, 1960).

The sputum showed numerous malignant cells, probably squamous in origin. Chest $x$-ray film (see Figure) showed a large tumour in the right upper lobe obstructing the upper-lobe bronchus with some deflation of the upper lobe. No lesion in the oesophagus, stomach, or duodenum was found on barium-meal examination. A radiological skeletal survey showed no bony metastases. $X$-ray examination of hands, feet, and teeth revealed moderate generalized decrease in bone density but no cortical erosions in the phalanges. There was some irregularity of the lateral parts of the lower radii and lower part of the humeri resembling hypertrophic pulmonary osteo- 